\title{
Morfoanatomia e ontogênese das sementes de espécies de Banisteriopsis C.B. Robinson e Diplopterys A. Juss. (Malpighiaceae) ${ }^{1}$
}

\author{
Letícia Silva Souto² e Denise Maria Trombert Oliveira ${ }^{3,4}$
}

Recebido em 9/05/2005. Aceito em 29/09/2007

\begin{abstract}
RESUMO - (Morfoanatomia e ontogênese das sementes de espécies de Banisteriopsis C.B. Robinson e Diplopterys A. Juss. (Malpighiaceae)). Banisteriopsis e Diplopterys apresentam em conjunto aproximadamente 100 espécies e ocorrem em todo o continente americano, especialmente na América do Sul. Pouco se conhece sobre a estrutura dos órgãos reprodutivos de Malpighiaceae e este trabalho objetiva analisar morfoanatômica e ontogeneticamente sementes de B. campestris, B. oxyclada, B. stellaris e D. pubipetala. Os óvulos são suspensos, subcampilótropos, bitegumentados e crassinucelados. O tegumento interno é mais curto que o externo, que forma a micrópila. O nucelo é muito amplo e se projeta pela micrópila, ficando em contato direto com o obturador funicular, estrutura menos conspícua em D. pubipetala. As sementes de Banisteriopsis e Diplopterys são pequenas, amarelo-escuras, com paquicalaza; na maturidade, o envoltório seminal encontra-se colapsado, distinguindo-se apenas a exotesta com compostos fenólicos e resíduos da vascularização; são sementes exalbuminosas e o embrião preenche toda a cavidade seminal; tem eixo embrionário reto e curto, com cotilédones carnosos bem desenvolvidos. A reserva embrionária é composta basicamente por lipídeos, havendo pequenos grãos de amido dispersos; muitas drusas também são observadas. A estrutura e desenvolvimento das sementes estudadas são muito semelhantes entre si e às demais Malpighiaceae já descritas. Constituem novos registros para a literatura a presença de obturador e de paquicalaza em Malpighiaceae.
\end{abstract}

Palavras-chave: semente, Banisteriopsis, Diplopterys, anatomia, morfologia

\begin{abstract}
Morphology, anatomy and ontogeny of the seeds of Banisteriopsis C.B. Robinson and Diplopterys A. Juss. (Malpighiaceae) species). Banisteriopsis and Diplopterys together have ca. 100 species and occur throughout the Americas, especially in South America. The structure of the reproductive organs of Malpighiaceae is poorly known, so this work aims to analyze the morphology, anatomy and ontogeny of the seeds of B. campestris, B. oxyclada, B. stellaris and D. pubipetala. The ovules are suspended, subcampylotropous, bitegmic and crassinucellate. The inner integument is shorter than outer, and only the latter constitutes the micropyle. The nucellus is very large and projects through micropyle, coming in contact with the funicular obturator which is less conspicuous in D. pubipetala. Banisteriopsis and Diplopterys have small, dark yellow pachychalazal seeds; at maturity, the seed coat collapses, and only the exotesta with phenolic compounds and vascular residues can be distinguished; the seeds are exalbuminous and the embryo fills the seminal chamber; it has a short, straight embryo axis, with well-developed fleshy cotyledons. The embryo reserve is composed basically of lipids, with small, scattered starch grains; many druses are also observed. Structure and development of these seeds are very similar to one another and to other Malpighiaceae already described. This is the first report of obturator and pachychalaza in Malpighiaceae.
\end{abstract}

Key words: seed, Banisteriopsis, Diplopterys, anatomy, morphology

\section{Introdução}

A morfologia de frutos e sementes normalmente mostra pequena plasticidade fenotípica e é, portanto, de grande importância taxonômica (Von Teichman \& Van Wyk 1991). Apesar disso, estudos com esses órgãos são escassos na literatura, principalmente os relacionados a espécies tropicais.

Malpighiaceae é uma família monofilética, com 1.200 espécies reunidas em 66 gêneros (Anderson 1990).
Apresenta distribuição pantropical, mas sua maior diversidade encontra-se no continente sul-americano (Judd et al. 1999); em recente levantamento, Mendonça et al. (1998) colocaram as Malpighiaceae entre as dez famílias mais bem representadas no bioma cerrado.

Segundo Corner (1976), as Malpighiaceae apresentam óvulos anátropos ou subcampilótropos, suspensos, bitegumentados e crassinucelados; a placentação é axial e ocorre um óvulo por lóculo. As sementes são normalmente pequenas, de formato

\footnotetext{
1 Parte da Dissertação de Mestrado da primeira Autora, Programa de Pós-graduação em Ciências Biológicas (Botânica), Universidade Estadual Paulista, Botucatu, SP, Brasil

2 Universidade Estadual Paulista, Instituto de Biociências, Departamento de Botânica, C. Postal 510, 18618-000 Botucatu, SP, Brasil

3 Universidade Federal de Minas Gerais, Instituto de Ciências Biológicas, Departamento de Botânica, Av. Antônio Carlos 6627, Pampulha, C. Postal 486, 31270-901 Belo Horizonte, MG, Brasil

4 Autor para correspondência: dmtoliveira@icb.ufmg.br
} 
obcônico ou piriforme, mais ou menos exalbuminosas, com tegumento reduzido, composto por tégmen fibroso e endotégmen esclerificado; segundo o autor, uma ou ambas as características podem desaparecer na ontogênese tegumentar. Corner (1976) destacou que são poucas as sementes de Malpighiaceae estudadas em detalhe, afirmativa que ainda hoje, passadas três décadas, mostra-se verdadeira. O embrião é variável, de reto a curvo, conforme indicado por Judd et al. (1999).

Banisteriopsis C.B. Rob. e Diplopterys A. Juss. são considerados gêneros irmãos, tanto pela similaridade da estrutura floral (Gates 1982) quanto pela análise de dados moleculares (Anderson \& Davis 2006); os dois gêneros são muito significativos dentro de Malpighiaceae, em função de possuírem, em conjunto, cerca de 100 espécies (Anderson \& Davis 2006). Esses gêneros têm distribuição exclusivamente neotropical, estando restritos apenas aos trópicos do continente americano, apresentando sua maior diversidade específica na região central do Brasil (Gates 1982). Como é típico da família, suas sementes são pequenas e estão inseridas em frutos espessos do tipo samarídeo ou noz. Embora sejam gêneros importantes em Malpighiaceae, não há na literatura qualquer estudo detalhado sobre a anatomia de suas sementes.

Considerando a escassez de trabalhos sobre a ontogênese de órgãos reprodutivos de Malpighiaceae e a importância do grupo para a vegetação do continente americano, em especial para o bioma cerrado, o objetivo deste trabalho é descrever, sob o ponto de vista ontogenético, a morfologia e anatomia das sementes de B. campestris, B. oxyclada, B. stellaris e Diplopterys pubipetala.

\section{Material e métodos}

Óvulos e sementes foram coletados de indivíduos de Banisteriopsis campestris (Adr. Jussieu) E.L. Little, B. oxyclada (Adr. Jussieu) B. Gates, B. stellaris (Grisebach.) B. Gates e Diplopterys pubipetala (A. Juss.) W.R. Anderson \& C. Cav. Davis (Malpighiaceae), ocorrentes em remanescentes de cerrado nos seguintes locais: km 3 da Rodovia Hipólito Martins (Castelinho), no município de Botucatu, SP $\left(23^{\circ} 02^{\prime} 51^{\prime \prime} \mathrm{S}\right.$ e 4831'18'W); estrada da Mina, município de Botucatu, SP (22 $42^{\circ} 38^{\prime \prime}$ S e $\left.48^{\circ} 18^{\prime} 35^{\prime \prime} \mathrm{W}\right)$; e áreas residuais de cerrado do município de Botucatu, SP (22051'22"S e

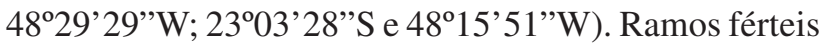
foram herborizados, identificados e registrados no Herbário "Irina D. Gemtchujnicov" (BOTU), respectivamente sob os números 25.304, 24.292, 24.289 e 24.291.

A morfologia das sementes foi descrita e ilustrada a partir de amostras de 50 unidades removidas de frutos coletados aleatoriamente de, no mínimo, cinco indivíduos. A nomenclatura utilizada foi baseada em Martin (1946), Corner (1976), Werker (1997) e Barroso et al. (1999).

Para o estudo anatômico, óvulos e sementes, nas diversas fases do desenvolvimento, foram separados de ovários e frutos, sendo fixados em FAA 50 (Johansen 1940) e armazenados em etanol $70 \%$. Foram preparadas lâminas permanentes, sendo as amostras desidratadas em série etílica, infiltradas em metacrilato Leica ${ }^{\circledR}$ segundo o protocolo do fabricante, seccionadas em micrótomo rotativo, coradas com azul de toluidina 0,05\%, pH 4,7 (O'Brien et al. 1964) e montadas em resina sintética.

Para os testes histoquímicos, foram utilizadas secções a mão livre de material fresco ou fixado, submetidas aos seguintes corantes e/ou reagentes: vermelho de rutênio, para identificar polissacarídeos diversos e pectinas (Jensen 1962); floroglucinol acrescido de ácido clorídrico, para evidenciar paredes lignificadas (Sass 1951); Sudan IV, para a localização de substâncias lipídicas; lugol, para a detecção de amido; cloreto férrico, acrescido de carbonato de sódio, para verificar a ocorrência de compostos fenólicos (Johansen 1940).

O material foi analisado em microscópio fotônico. Os resultados foram registrados por meio de fotomicrografias preparadas em fotomicroscópio Olympus com câmara digital Olympus acoplada, sendo as escalas produzidas de modo convencional.

\section{Resultados}

As sementes das espécies estudadas de Banisteriopsis e Diplopterys são semelhantes em todas as fases do desenvolvimento. Assim sendo, apresentase uma descrição única do desenvolvimento dessas sementes, destacando-se os caracteres divergentes.

Óvulo do botão floral e flor em antese - Nas espécies estudadas, a placentação é axial com óvulos pêndulos e unitários em cada lóculo (Fig. 1). O óvulo é subcampilótropo (Fig. 2), bitegumentado (Fig. 2-5) e crassinucelado (Fig. 1-7).

O tegumento externo é formado por cerca de quatro camadas celulares na região calazal (Fig. 4) e duas camadas próximas à micrópila (Fig. 5); a epiderme externa é mais diferenciada, formada por células volumosas, de paredes delgadas, retangulares em secção longitudinal e com grande densidade de compostos fenólicos (Fig. 2-4), exceto junto à micrópila (Fig. 2); o mesofilo é formado por células ligeiramente alongadas longitudinalmente, também de paredes delgadas, vacuolizadas e com núcleo bem evidente. A epiderme interna é indiferenciada do mesofilo (Fig. 4). 
$\mathrm{O}$ tegumento interno também tem cerca de quatro camadas celulares (Fig. 4), podendo restringir-se, na micrópila, a duas camadas (Fig. 5). Tanto a epiderme externa quanto a interna são formadas por células cubóides (Fig. 4), com citoplasma mais denso próximo à calaza; seu formato vai se tornando mais irregular à medida que se aproxima da micrópila, onde é composto somente pela epiderme externa e interna (Fig. 5); o mesofilo é constituído por até duas camadas de células, maiores que as da epiderme, de formato irregular e cito- plasma vacuolizado (Fig. 4). Como o tegumento interno é mais curto, apenas o tegumento externo reveste a extremidade micropilar, sendo a micrópila constituída por amplo poro (Fig. 5). Idioblastos cristalíferos com drusas são observados nos mesofilo de ambos os tegumentos.

O nucelo é muito amplo e apresenta células de formatos e tamanhos variáveis, paredes delgadas, vacuoma desenvolvido e núcleo pequeno e evidente (Fig. 2, 4-8), projetando diversas camadas celulares pela micrópila (Fig. 2, 5-6). Na calaza, ocorre um pequeno
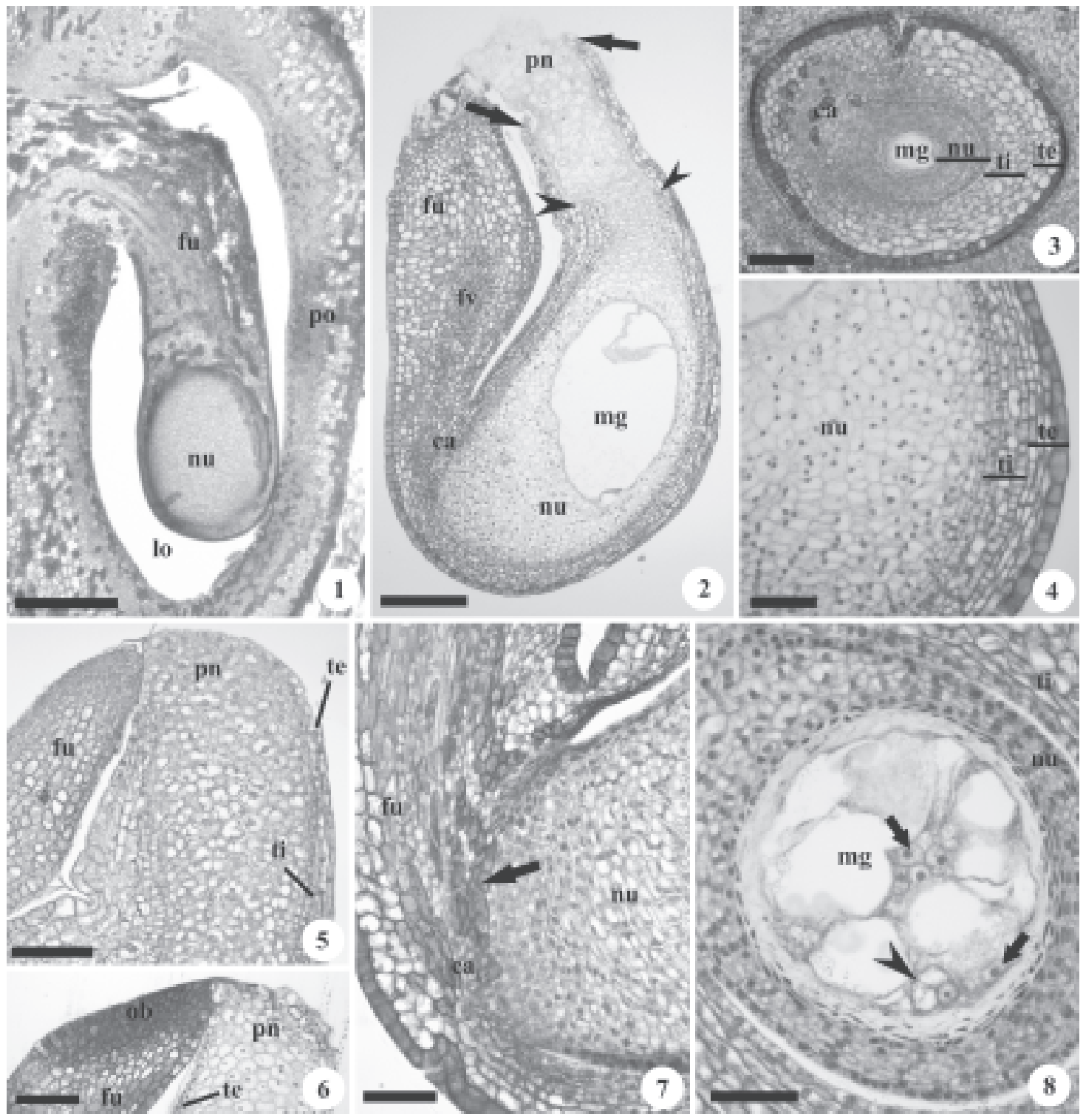

Figuras 1-8. Óvulos de botões florais e flores em antese de Banisteriopsis campestris (Adr. Jussieu) E.L. Little (2, 4), Banisteriopsis oxyclada (Adr. Jussieu) B. Gates $(1,3,7)$, Banisteriopsis stellaris (Grisebach.) B. Gates $(6,8)$ e Diplopterys pubipetala (A. Juss.) W.R. Anderson \& C. Cav. Davis (5). Secções longitudinais (1-2, 4-8). Secção transversal (3). 1. Ovário com óvulo pêndulo em placentação axial. 2. Óvulo com nítida projeção do nucelo pela micrópila (ponta de seta: extremidade do tegumento interno; seta: extremidade do tegumento externo). 3 . Região calazal. 4. Detalhe dos tegumentos e nucelo, próximos à calaza. 5. Micrópila, mostrando a projeção do nucelo e o tegumento interno mais curto que o externo. 6. Detalhe do obturador, em contato direto deste com as células projetadas do nucelo. 7. Região calazal, destacando a hipóstase (seta). 8. Óvulo de botão floral, com núcleos livres do endosperma (seta) e zigoto embrionário voltado para a região micropilar (ponta de seta). (ca: calaza, fu: funículo, fv: feixe vascular, lo: lóculo, mg: megagametofito, nu: nucelo, ob: obturador, pn: projeção do nucelo, po: parede ovariana, te: tegumento externo, ti: tegumento interno). Barras: $500 \mu \mathrm{m}(1), 150 \mu \mathrm{m}(2-3), 100 \mu \mathrm{m}(5-6), 50 \mu \mathrm{m}(4,7-8)$. 
acúmulo de compostos fenólicos, constituindo uma hipóstase pouco conspícua (Fig. 7). O funículo é longo e espesso, formado por células parenquimáticas (Fig. 1-2), com muitos idioblastos fenólicos e cristais do tipo drusa; observa-se, ainda, um feixe vascular anficrival. Na região de inserção do funículo no ovário, ocorre um adensamento de células pequenas, com leve alongamento longitudinal, de parede delgada e citoplasma denso (Fig. 6), acumulando substâncias pécticas. Este tecido fica em contato direto com as células projetadas do nucelo, constituindo um obturador funicular. Em D. pubipetala, esta estrutura é menos conspícua.

Nesta fase, já se observa a presença de endosperma nuclear em formação e do zigoto embrionário (Fig. 8).

Semente em desenvolvimento - Como o óvulo, a semente é subcampilótropa (Fig. 9-10), com ampla calaza e rafe indistinta desde o início do desenvolvimento (Fig. 9). Durante esta fase, a calaza é ampliada, constituindo uma região paquicalazal que abrange cerca de metade da semente (Fig. 10).

Os tegumentos não apresentam divisões periclinais, permanecendo com o mesmo número de camadas dos óvulos (Fig. 11). Divisões anticlinais esparsas associam-se ao aumento do volume celular por vacuolização, acomodando o crescimento da semente. Durante o desenvolvimento, os tegumentos concrescem, constituindo sementes unitegumentadas. Este concrescimento acontece de modo gradual, sendo observado apenas em algumas regiões no primeiro momento, quando a maior parte dos tegumentos continua individualizada. Com a seqüência do desenvolvimento, o concrescimento atinge toda a extensão da semente, tornando o tegumento único.

Próximo à maturidade, observa-se a exotesta unisseriada, com células alongadas verticalmente, as quais apresentam grande concentração de compostos fenólicos (Fig. 12). A mesotesta é composta por três a sete camadas de células, mais ou menos alongadas horizontalmente (Fig. 12). Uma camada de células com compostos fenólicos pode aparecer em algumas regiões, indicando a porção onde houve o concrescimento dos tegumentos (Fig. 12).

O nucelo passa por divisões celulares, em planos variáveis, e por grande vacuolização celular (Fig. 13), sendo o responsável pelo aumento de volume da semente durante o início do seu desenvolvimento (Fig. 9). Suas células vão se tornando maiores e vacuolizadas,
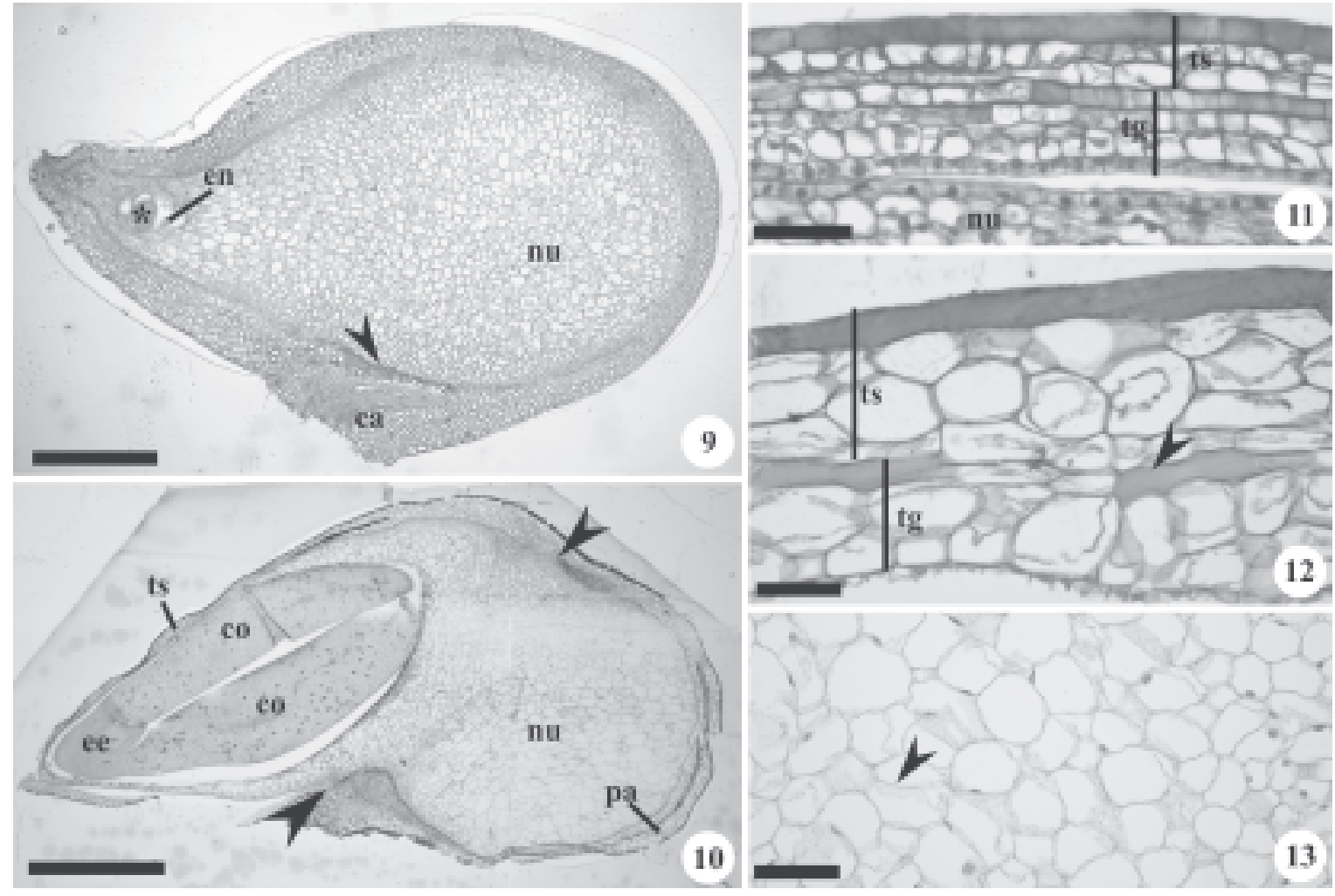

Figuras 9-13. Semente em desenvolvimento de Banisteriopsis stellaris (Grisebach.) B. Gates (10-12) e Diplopterys pubipetala (A. Juss.) W.R. Anderson \& C.Cav. Davis (9, 13) em secções longitudinais. 9-10. Vista geral. 9. Semente com embrião globular (asterisco). 10. Semente com embrião em torpedo; no envoltório, notar a presença da testa e paquicalaza (ponta de seta: delimitação entre testa e paquicalaza). 11. Tegumentos no início do desenvolvimento da semente, com testa e tégmen individualizados. 12. Tegumentos mostrando células que começam a colapsar (seta) e células fenólicas exotégmicas (ponta de seta). 13. Nucelo com divisões celulares (ponta de seta). (ca: calaza, co: cotilédone, ee: eixo embrionário, en: endosperma, nu: nucelo, pa: paquicalaza, tg: tégmen, ts: testa). Barras: 2 mm (10), $500 \mu \mathrm{m}(9), 100 \mu \mathrm{m}(13), 50 \mu \mathrm{m}(11-12)$. 
mantendo a parede delgada. O endosperma não se multiplica muito e torna-se rapidamente celularizado.

$\mathrm{O}$ zigoto embrionário apresenta divisões celulares e dá origem, seqüiencialmente, ao embrião com aspecto globular (Fig. 9, 14), cordiforme (Fig. 15) e em torpedo (Fig. 10,16). Até a fase cordiforme, é nítida a presença do suspensor, constituído por uma ampla e vacuolizada célula micropilar e por células pequenas e mais densas, dispostas linearmente, sobre as quais se insere o embrião propriamente dito (Fig. 14-15).

Semente madura - A semente é pequena e de coloração amarelo-escura; em $D$. pubipetala, a semente tem formato arredondado, enquanto que nas espécies de Banisteriopsis é mais alongada e achatada. As regiões micropilar e hilar apresentam coloração mais escura que o restante do envoltório e o funículo espesso é, eventualmente, mantido junto à semente (Fig. 20). A semente é retida em frutos do tipo samarídeo, muito lignificado, o que torna difícil sua separação.

$\mathrm{O}$ envoltório seminal (tanto a testa quanto a paquicalaza) encontra-se colapsado (Fig. 17-18), podendo ser distinguida apenas a exotesta (Fig. 19) com compostos fenólicos. Podem-se observar resquícios da vascularização, que indicam a porção paquicalazal do envoltório (Fig. 17). A semente é exalbuminosa (Fig. 17-18) e o nucelo foi intensamente consumido, podendo persistir pequenos resíduos de células nucelares (Fig. 19).

O embrião ocupa toda a cavidade seminal, é reto, tem cotilédones carnosos bem desenvolvidos (Fig. 17-18) e eixo hipocótilo-radícula curto e afilado (Fig. 17). Os dois cotilédones são grandes, carnosos, plano-convexos e aproximadamente simétricos (Fig. 18). Apresentam protoderme unisseriada, com células pequenas e cubóides, de parede pecto-celulósica delgada, citoplasma denso e núcleo evidente. O meristema fundamental é constituído por células mais volumosas e de formato aproximadamente isodiamétrico (Fig. 22). Imersos no meristema fundamental, observam-se pequenos cordões procambiais.

No ápice radicular do eixo embrionário, verifica-se amplo primórdio de coifa, formado por células dispostas em fileiras radiais próximas à região do promeristema e mais irregulares na porção distal (Fig. 21). A radícula é curta (Fig. 21), sendo difícil fazer a distinção entre esta e o hipocótilo. O nó cotiledonar é estreito e o epicótilo indistinto. A plúmula é indiferenciada, sendo composta apenas pelo meristema apical caulinar, sem qualquer indício de primórdio foliar (Fig. 22).

Em todo o eixo embrionário, a protoderme é unisseriada e tem células menores que as demais, densas e cubóides; o meristema fundamental é composto por células mais isodiamétricas e vacuolizadas que as da protoderme, embora seu citoplasma também seja denso; o procâmbio é formado por células ligeiramente alongadas longitudinalmente, com a distribuição típica (Fig. 21-22).

A reserva encontrada em todo o embrião é composta basicamente por lipídeos, havendo somente pequenos

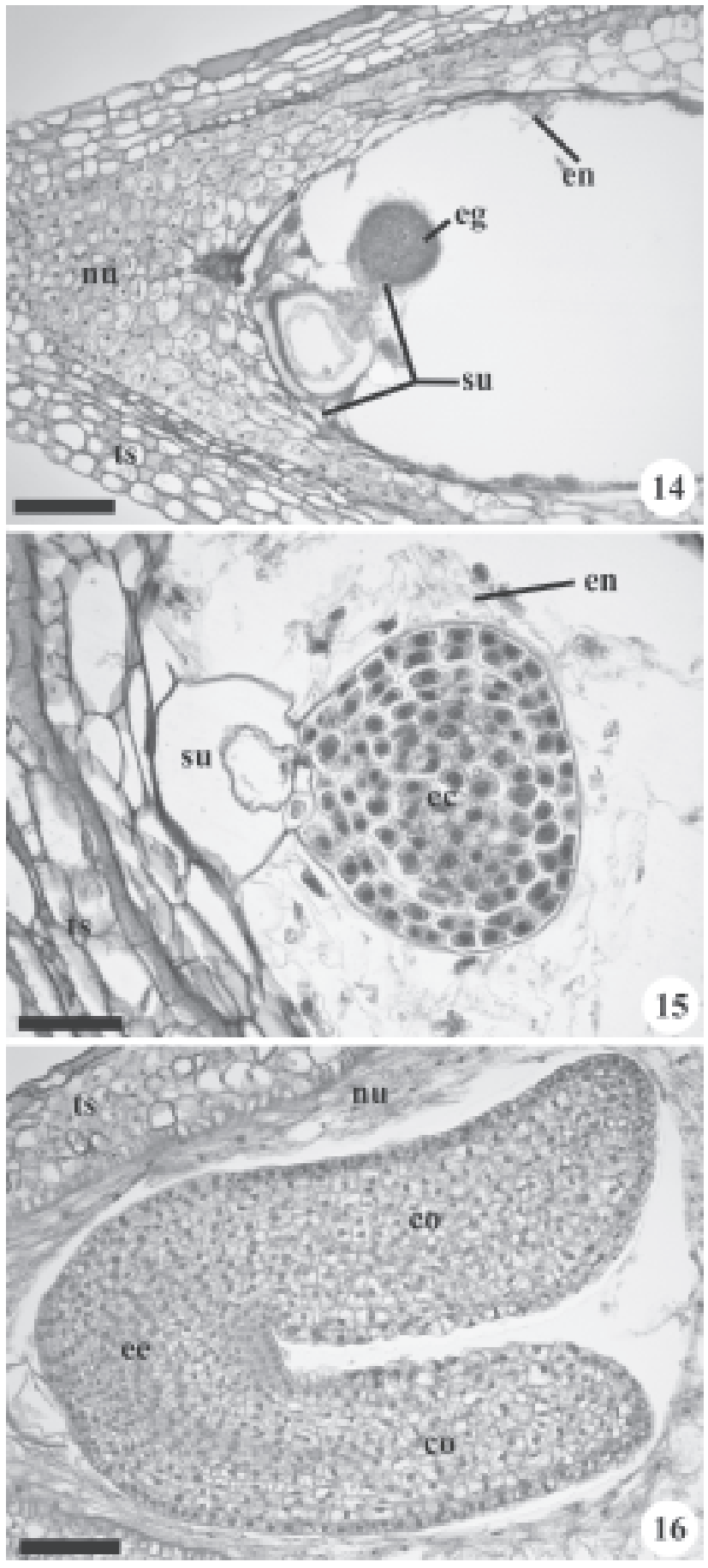

Figuras 14-16. Semente em desenvolvimento de Banisteriopsis stellaris (Grisebach.) B. Gates (14), Banisteriopsis oxyclada (Adr. Jussieu) B. Gates (15) e Diplopterys pubipetala (A. Juss.) W.R. Anderson \& C. Cav. Davis (16) em secções longitudinais. 14. Região micropilar com embrião globular e suspensor. 15. Embrião cordiforme. 16. Embrião em torpedo. (co: cotilédone, ec: embrião cordiforme, ee: eixo embrionário, eg: embrião globular, en: endosperma, nu: nucelo, su: suspensor, ts: testa). Barras: $100 \mu \mathrm{m}(14,16), 50 \mu \mathrm{m}(15)$. 


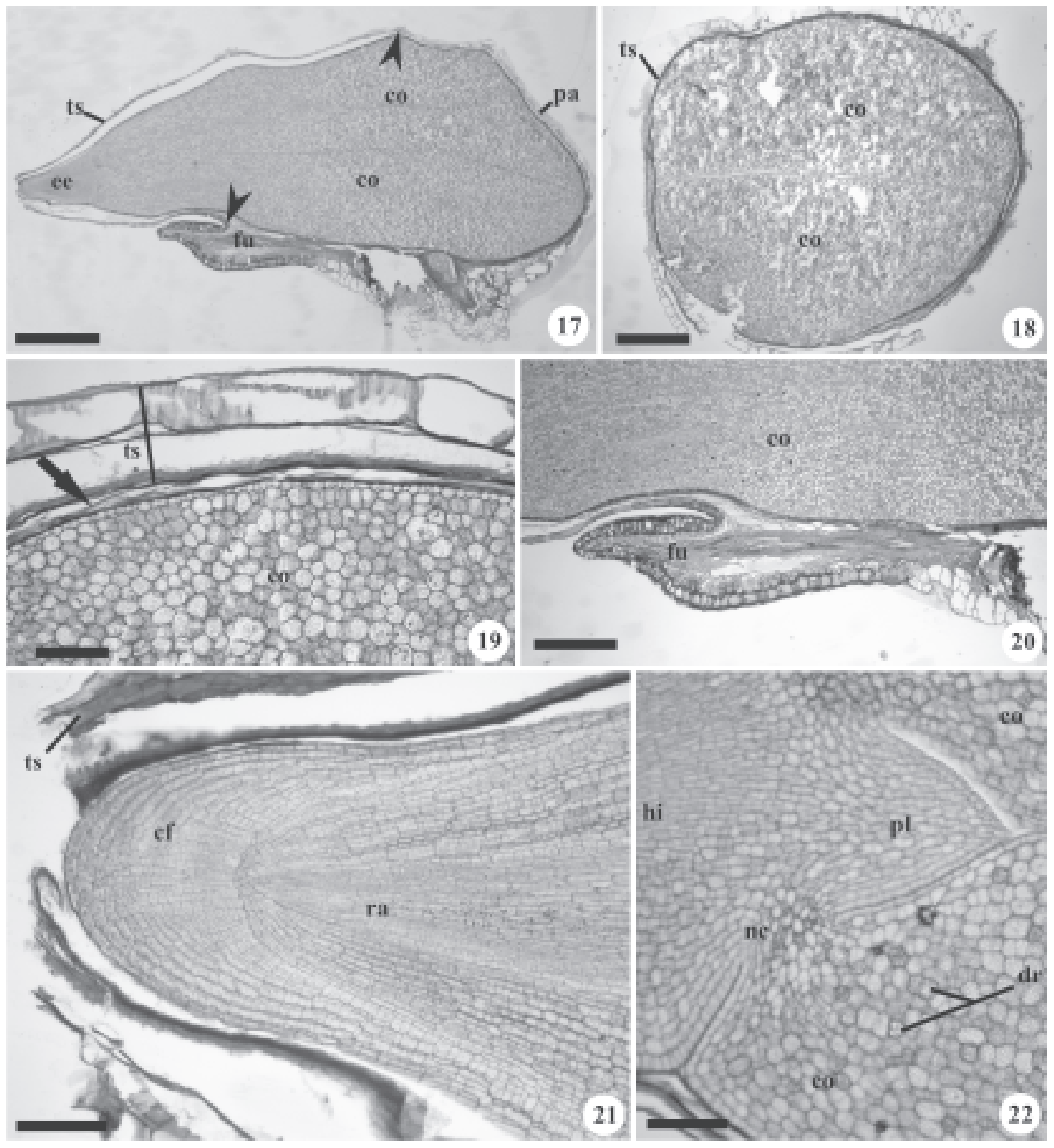

Figuras 17-22. Semente madura de Banisteriopsis oxyclada (Adr. Jussieu) B. Gates. Secções longitudinais (17, 19-22). Secção transversal (18). 17-18. Vista geral (ponta de seta: delimitação entre testa e paquicalaza). 19. Testa e cotilédone; notar resquícios de células nucelares (seta). 20. Região hilar. 21. Radícula; observar a testa colapsada e o arranjo radial das células da coifa. 22. Nó cotiledonar e plúmula indiferenciada. (cf: coifa, co: cotilédone, dr: drusa, ee: eixo embrionário, fu: funículo, hi: hipocótilo, nc: nó cotiledonar, pa: paquicalaza, pl: plúmula, ra: radícula, ts: testa). Barras: $1 \mathrm{~mm}(17), 500 \mu \mathrm{m}(18,20), 100 \mu \mathrm{m}(19,21-22)$.

grãos de amido dispersos. Muitas drusas são observadas no meristema fundamental de todo o embrião, com maior freqüência nos cotilédones (Fig. 22).

\section{Discussão}

Nas três espécies de Banisteriopsis e em D. pubipetala, óvulos e sementes apresentam uma constância de caracteres, não ocorrendo nenhuma modificação estrutural ou do desenvolvimento que possa distinguir as espécies estudadas ou mesmo os dois gêneros. Apesar de Souto \& Oliveira (dados não publicados) terem destacado diferenças significativas entre os pericarpos de espécies dos dois gêneros, respaldando o recente trabalho que transformou Banisteriopsis pubipetala (A. Juss.) Cuatrc. em D. pubipetala (Anderson \& Davis 2006), a constância de caracteres estruturais de óvulos e sementes é esperada 
e tem sido destacada na literatura, tendo em vista que estes são os órgãos mais conservadores entre os reprodutivos, os quais exibem menor variação dentro dos táxons (Von Teichman \& Van Wyk 1991).

A estrutura do óvulo das espécies estudadas corrobora o descrito por Corner (1976) para a família, encontrando-se aqui óvulos subcampilótropos, suspensos, bitegumentados e crassinucelados. A presença de funículo longo e bem desenvolvido, como o das espécies estudadas, foi também encontrada em Janusia guaranitica (St. Hil.) Juss. (Lorenzo 1981), Malpighia emarginata DC. (Laskowsky \& Bautista 1999), M. glabra L. (Nacif et al. 1996) e Lophantera lactescens Ducke (Paoli 1997). O grau de desenvolvimento do funículo é caráter irregularmente variável na família, não parecendo guardar relação com o tipo de óvulo, já que Byrsonima intermedia A. Juss., estudada por Souto \& Oliveira (2005), apresenta óvulo subcampilótropo como as espécies aqui estudadas, mas tem funículo curto.

Os óvulos de Malpighiaceae são frequientemente descritos como bitegumentados (Corner 1976; Nacif et al. 1996; Paoli 1997; Souto \& Oliveira 2005), característica também encontrada nas três espécies de Banisteriopsis e em D. pubipetala. Apesar de apresentar óvulo unitegumentado, J. guaranitica apresenta a epiderme externa formada por células volumosas e taniníferas (Lorenzo 1981), semelhante à epiderme externa do tegumento externo das quatro espécies estudadas.

A ocorrência de nucelo projetado pela micrópila é tida como caráter constante na família Malpighiaceae (Corner 1976) e já foi relatada pelo autor para espécies de Hiptage Gaertn. e Stigmatophyllum, para B. intermedia (Souto \& Oliveira 2005) e para J. guaranitica (Lorenzo 1981). Entretanto, o contato direto das células projetadas do nucelo com o obturador de origem funicular não havia sido descrito para a família até o presente trabalho. Apesar da ocorrência de obturador não ser registrada anteriormente para as Malpighiaceae, ele é típico das Euphorbiaceae (Corner 1976), família também pertencente a Malpighiales de acordo com o APG (2003).

A ocorrência de flores cleistógamas é referida por Ritzerow (1908) para vários gêneros de Malpighiaceae, as quais apresentam morfologia diferente das flores casmógamas. Para Banisteriopsis e Diplopterys, não há relato de flores cleistógamas, apesar deste trabalho registrar, já no estágio de botão floral, a ocorrência de óvulos com zigoto embrionário constituído. Subba Rao (1939) descreveu a embriologia de Hiptage madablota Gaertn., Banisteria laurifolia L. e Stigmaphyllum aristatum L. (Malpighiaceae), relatando a ausência de fecundação, embora haja produção de embrião. A ocorrência de embrião formado por apomixia foi registrada para J. guaranitica (Lorenzo 1981), Thryallis glauca Kuntze (Singh 1959) e Peixotoa reticulata Griseb. (Anderson 1982). Não foi objetivo deste trabalho identificar a origem do embrião formado, nem a efetiva ocorrência da fecundação; consideram-se importantes, portanto, trabalhos futuros relacionados à embriologia stricto sensu desses gêneros, de modo a esclarecer a origem do embrião e a possível ocorrência de apomixia.

Durante a formação da semente das quatro espécies estudadas, verificou-se a formação de paquicalaza, processo até então não referido para as Malpighiaceae, sendo este o primeiro relato para a família. Nas sementes paquicalazais, como as espécies aqui estudadas, a calaza se amplia formando grande parte do envoltório seminal (Werker 1997). Segundo Corner (1976) e Von Teichman \& Van Wyk (1991), sementes paquicalazais normalmente desenvolvem-se a partir de óvulos bitegumentados. A paquicalaza está também associada a outras características ancestrais, como óvulos crassinucelados e endosperma com desenvolvimento nuclear; em sementes pequenas, a estrutura ainda é correlacionada à ausência de endosperma (Von Teichman \& Van Wyk 1991). Todas as características relatadas para as sementes paquicalazais foram observadas neste trabalho.

Segundo Corner (1976), as sementes de Malpighiaceae apresentam tegumento reduzido, sendo essa característica corroborada pelas sementes de Banisteriopsis e Diplopterys aqui estudadas. Tegumentos reduzidos são muito freqüentes em espécies que apresentam a semente inclusa em pericarpo rígido, caso em que a pequena diferenciação tegumentar estaria relacionada à transferência da função de proteção, normalmente exercida pelos tegumentos, para os tecidos pericárpicos. Tal característica tem sido registrada com freqüência em espécies produtoras de sâmaras, como Tipuana tipu (Benth.) O. Kuntze (Martins \& Oliveira 2001) e de frutos drupóides, como Malpighia glabra (Nacif et al. 1996) e Byrsonima intermedia (Souto \& Oliveira 2005).

Apesar das sementes das espécies estudadas não apresentarem camada mecânica no tegumento, elas podem ser consideradas exotestais, segundo a classificação proposta por Corner (1976), por apresentarem exotesta formada por células levemente espessadas e com acúmulo de compostos fenólicos, que se mantém evidente mesmo na maturidade.

Seguindo-se a terminologia de Martin (1946), o embrião das três espécies de Banisteriopsis e de Diplopterys é dominante e espatulado. De acordo com Barroso et al. (1999), o embrião é dito cotiledonar, por distinguirem-se o eixo hipocótilo-radícula dos 
cotilédones, contínuo e espatulado. Chama a atenção que o embrião de Malpighiaceae apresenta morfologia bem variada; Malpighia glabra, assim como as espécies estudadas, apresenta embrião reto (Nacif et al. 1996), Lophantera lactescens possui embrião dobrado (Paoli 1997), enquanto que $B$. intermedia tem embrião espiralado (Souto \& Oliveira 2005). Apesar da variação na morfologia do embrião, as espécies supracitadas de Malpighiaceae apresentam cotilédones bem desenvolvidos e que acumulam reserva energética. A ocorrência de cotilédones bem desenvolvidos, associada à ausência de endosperma na maturidade de todas as espécies avaliadas na literatura (Corner 1976; Lorenzo 1981; Nacif et al. 1996; Paoli 1997; Souto \& Oliveira 2005) e neste trabalho, pode indicar que o caráter exalbuminoso seja comum a toda a família.

Segundo Nacif et al. (1996), Malpighia glabra apresenta reserva lipídica e protéica; Souto \& Oliveira (2005) registram que a reserva de $B$. intermedia apresenta lipídeos e amido. Já as três espécies de Banisteriopsis e D. pubipetala acumulam lipídeos e exibem apenas traços de amido. Verifica-se, portanto que, embora a reserva energética presente nos cotilédones das Malpighiaceae seja de composição variável, a ocorrência de lipídeos tem sido constantemente destacada.

\section{Agradecimentos}

Ao CNPq, pela bolsa de mestrado concedida a L.S. Souto e pela bolsa de produtividade em pesquisa de D.M.T. Oliveira; à FAPESP-Programa BIOTA (Proc. 00/12469-3), pelo auxílio financeiro; à Dra. Maria Candida Henrique Mamede, pela identificação das espécies; e ao Sr. Clemente José Campos pelo auxílio nas coletas.

\section{Referências bibliográficas}

Anderson, C. 1982. A monograph of the genus Peixotoa (Malpighiaceae). Contributions of the University of Michigan Herbarium 15: 1-92.

Anderson, W.R. 1990. The origin of the Malpighiaceae: the evidence from morphology. Memoirs of The New York Botanical Garden 64: 210-224.

Anderson, W.R. \& Davis, C.C. 2006. Expansion of Diplopterys at the expense of Banisteriopsis (Malpighiaceae). Harvard Papers in Botany 11: 1-16.

APG. 2003. An update of the Angiosperm Phylogeny Group classification for the orders and families of flowering plants: APG II. Botanical Journal of the Linnean Society 141: 399-436.
Barroso, G.M.; Morim, M.P.; Peixoto, A.L. \& Ichaso, C.L.F. 1999. Frutos e sementes. Morfologia aplicada à sistemática de dicotiledôneas. Viçosa, Editora UFV.

Corner, E.J.H. 1976. The seeds of dicotyledons. 2v. Cambridge, University Press.

Gates, B. 1982. Banisteriopsis, Diplopterys (Malpighiaceae). Flora Neotropica, Monograph 30: 1-236.

Jensen, W.A. 1962. Botanical histochemistry. Principles and pratice. San Francisco, W.H. Freeman.

Johansen, D.A. 1940. Plant microtechnique. New York, McGrawHill Book.

Judd, W.S.; Campbell, C.S.; Kellog, E.A. \& Stevens, P.F. 1999. Plant Systematics. A phylogenetic approach. Sunderland, Sinauer Associates.

Laskowski, L.E. \& Bautista, D. 1999. Caracteristicas anatomicas de la flor del semeruco (Malpighia emarginata DC.). Ernstia 9: 19-36.

Lorenzo, E. 1981. Sobre la inflorescencia, morfologia floral y embriologia de Janusia guaranitica (Malpighiaceae). Kurtziana 14: 101-124.

Martin, A.C. 1946. The comparative internal morphology of seeds. American Midland Naturalist 36: 513-660.

Martins, M.A.G. \& Oliveira, D.M.T. 2001. Morfo-anatomia e ontogênese do fruto e da semente de Tipuana tipu (Benth.) O. Kuntze (Fabaceae: Faboideae). Revista Brasileira de Botânica 24: 109-121.

Mendonça, R.C.; Felfili, J.M.; Walter, B.M.T.; Silva Júnior, M.C.; Rezende, A.V.; Filgueiras, T.S. \& Nogueira, P.E. 1998. Flora vascular do cerrado. Pp. 289-556. In: S.M. Sano \& S.P. Almeida (eds.). Cerrado. Ambiente e flora. Planaltina, EMBRAPACPAC.

Nacif, S.R.; Guardia, M.C. \& Moraes, P.L.R. 1996. Morfologia e anatomia das sementes de acerola (Malpighia glabra L. Malpighiaceae). Revista Ceres 43: 597-610.

O’Brien, T.P.; Feder, N. \& Mccully, M.E. 1964. Polychromatic staining of plant cell walls by toluidine blue O. Protoplasma 59: $368-373$.

Paoli, A.A.S. 1997. Morfo-anatomia de frutos e sementes de Lophantera lactescens Ducke (Malpighiaceae). Revista Brasileira de Sementes 19: 238-244.

Ritzerow, H. 1908. Über Bau und Befruchtung kleistogamer Blüten. Flora, Regensburg 98: 163-212 apud Mamede, M.C.H. 1993. Estudo comparativo de flores casmógamas, cleistógamas e de frutos de Camarea affinis St.-Hil. (Malpighiaceae). Acta Botanica Brasilica 7: 21-31.

Sass, J.E. 1951. Botanical microtecnique. Ames, Iowa State University.

Singh, B. 1959. Studies in the family Malpighiaceae. 1. The morphology of Thryallis glauca Kuntze. Horticultural Advanced 3: 1-19.

Souto, L.S. \& Oliveira, D.M.T. 2005. Morfoanatomia e ontogênese do fruto e semente de Byrsonima intermedia A. Juss. (Malpighiaceae). Revista Brasileira de Botânica 28: 697-712.

Subba Rao, A.M. 1939. Studies in the Malpighiaceae: I. Embryo-sac development and embryogeny in the genera Hiptage, Banisteria and Stigmaphyllum. Journal of the Indian Botanical Society 18: $146-156$.

Von Teichman, I. \& Van Wyk, A.E. 1991. Trends in the evolution of dicotyledonous seeds based on character associations, with special reference to pachychalazy and recalcitrance. Botanical Journal of the Linnean Society 105: 211-237.

Werker, 1997. Seed anatomy. Berlin, Gebrüder Borntraeger. (Handbuch der Pflanzenanatomie).

Versão eletrônica do artigo em www.scielo.br/abb e http://www.botanica.org.br/acta/ojs 